\begin{tabular}{|l|l|}
\hline AB0379 & IS MYCOPHENOLATE SODIUM (MYFORTIC) \\
SIMILARLY EFFECTIVE AS MYCOPHENOLATE \\
MOFETIL (CELLCEPT) IN TREATMENT OF LUPUS \\
NEPHRITIS? EXPERIENCE FROM NON-MEDICAL \\
SWITCHING REAL WORLD DATA IN TAIWAN
\end{tabular}

W. N. Huang ${ }^{1}$, Y. M. Chen ${ }^{1}$, W. T. Hung ${ }^{1}$, K. T. Tang ${ }^{1}$, Y. W. Liao ${ }^{1}$, Y. H. Chen ${ }^{1}$. ${ }^{1}$ Taichung Veterans General Hospital, Division of Allergy, Immunology and Rheumatology, Taichung, Taiwan, Republic of China

Background: Lupus nephritis is the most important predictive factor of morbidity and mortality in SLE. Though Mycophenolate mofetil is recommended for induction and maintenance treatment of class III, IV V lupus nephritis, it is not approved by US or Taiwan FDA (TFDA). In previous reports of kidney transplantation, no efficacy differences were observed between mycophenolate sodium (Myfortic) and mycophenolate mofetil (Cellcept). However, no clinical trial was conducted to compare these two widely-used mycophenolic acid derivatives in lupus nephritis. In December, 2016, TFDA approved Mycophenolate sodium in treatment of lupus nephritis. For reimbursement issue, patients treated with mycophenolate mofetil were non-medically switched to mycophenolate sodium in Taiwan.

Objectives: To compare the treatment efficacy of mycophenolate mofetil and mycophenolate sodium in lupus nephritis patients with non-medical switching

Methods: Between 2016 and 2018, a retrospective observational study enrolled 50 biopsy-proven LN patients in Taichung Veterans General Hospital, Taiwan. All these patients were initially treated with Cellcept for at least one year. Treatment response was evaluated by urinalysis and daily urine protein one year before and after switching to Myfortic.

Results: Before switching, $72 \%$ patients were classified as responder if complete remission or partial remission were achieved, while $28 \%$ patients were categorized as non-responders (Table 1). After switching to Myfortic, $75 \%$ of the responder group achieved or maintained complete remission or partial response. In for non-responder group, $85.7 \%$ exhibited complete remission or partial response (Table 2). We did not observe new safety signals after switching.

Table 1. Comparisons demographics and renal pathologies of responder and non-responder groups

\begin{tabular}{lcccc}
\hline & $\begin{array}{c}\text { Non-responder } \\
\mathbf{( N = 1 4 )}\end{array}$ & $\begin{array}{c}\text { Responder* } \\
\mathbf{( N = 3 6 )}\end{array}$ & $\begin{array}{c}\text { Total } \\
(\mathbf{n}=\mathbf{5 0 )}\end{array}$ & $p$ value \\
\hline Age & $31.12 \pm 11.48$ & $32.58 \pm 9.39$ & & 0.660 \\
Female & $23(88.5 \%)$ & $20(76.9 \%)$ & $43(82.7 \%)$ & 0.465 \\
Daily urine protein (g) & $4.44 \pm 4.40$ & $4.43 \pm 3.81$ & & 0.835 \\
Creatine (mg/dl) & $1.44 \pm 0.92$ & $1.22 \pm 1.16$ & & 0.212 \\
Renal pathology class & & & & 0.649 \\
III & $6(23.1 \%)$ & $4(15.4 \%)$ & $10(19.2 \%)$ & \\
III+V & $2(7.7 \%)$ & $4(15.4 \%)$ & $6(11.5 \%)$ & \\
IV & $16(61.5 \%)$ & $15(57.7 \%)$ & $31(59.6 \%)$ & \\
IV+V & $2(7.7 \%)$ & $3(11.5 \%)$ & $5(9.6 \%)$ & \\
\hline
\end{tabular}

${ }^{*}$ complete remission and partial remission.

Table 2. Response rates of non-medical Switch from Cellcept to Myfortic

\begin{tabular}{lccr}
\hline \multicolumn{3}{c}{$\begin{array}{c}\text { Initial treatment with } \\
\text { Cellcept }\end{array}$} & \\
\hline & Non-responder & Responder & $p$ value \\
\hline Non-medical switch to & & & 0.705 \\
$\begin{array}{l}\text { Myfortic } \\
\text { Non-responder }\end{array}$ & $2(14.3)$ & $9(25)$ & \\
Responder & $12(85.7)$ & $27(75)$ & \\
\hline
\end{tabular}

Conclusion: This real-world data indicated similar efficacy of Cellcept and Myfortic. Further prospective study is needed to confirm our findings. Disclosure of Interests: None declared

DOI: 10.1136/annrheumdis-2020-eular.2325

\section{AB0380 \\ THERAPEUTIC CHOICES AND OUTCOMES IN CHINESE PATIENTS WITH SEROLOGICALLY ACTIVE CLINICALLY QUIESCENT SYSTEMIC LUPUS ERYTHEMATOSUS}

H. Huang ${ }^{1}$, L. Mu ${ }^{2}$, Z. Zhang ${ }^{1}$, Y. Hao ${ }^{1}$, W. Zhou ${ }^{1} .{ }^{1}$ Peking University First Hospital, Beijing, China; ${ }^{1}$ Peking University First Hospital, Beijing, China

Background: Patients with systemic lupus erythematosus (SLE) who achieved the clinical state as serologically active clinically quiescent (SACQ). It appears to account for $6-12 \%$ of all patients with SLE, but there is disagreement about whether such patients are indeed clinically stable [1-3], especially in Chinese patients. And there is no conclusion as to what kind of treatment should be taken for such patients.

Objectives: To clarify the frequency and outcome of SACQ patients in lupus. And to identify factors associated with the flare of disease.

Methods: Clinical data of patients diagnosed as SLE and followed in Peking University First Hospital from 2009 to 2015 were retrospectively reviewed. 682 patients with systemic lupus erythematosus who were followed up for more than 6 months at Peking University First Hospital from January 2007 to December 2015 were summarized. SACQ was defined as an at least a 6-month period with persistent serologic activity and without clinical activity and could be taking a daily dose of prednisone or equivalent less than $7.5 \mathrm{mg}$. Serologically quiescent clinically quiescent (SQCQ) patients and serologically active clinically active (SACA) patients served as control groups. Data including demographics, initial symptoms, duration to $S A C Q$, treatments before and after $S A C Q$, and characteristics of the flare group were analyzed.

Results: Of the 682 patients, 170 were SACQ patients (24.9\%), 187 were SQCQ patients, and 325 were SACA patients (47.7\%). SQCQ patients $(38.61 \pm 15.08$ years old) were older at study start than SACQ patients $(38.61 \pm 15.08$ years vs. $32.09 \pm 14.35$ years, $p<0.001$ ), but there was no significant difference between that of SACQ and SACA patients. 56 of the 170 SACQ patients (32.9\%) experienced flare. Corticosteroids (OR $1.317,95 \% \mathrm{Cl} 1.131$ to $1.534 ; \mathrm{p}<0.001$ ) was an independent risk factor for flare, while antimalarials (OR $0.265,95 \% \mathrm{Cl} 0.118$ to 0.599; $p=0.001$ ) and immunosuppressants (OR $0.316,95 \% \mathrm{Cl} 0.149$ to 0.670 $\mathrm{p}=0.003$ ) were protective factors.

Conclusion: About one third of SLE patients with SACQ experience flare, more than that of patients with SQCQ. Thus, approach to prevent relapse in SACQ patient is required. Maintenance therapy of hydroxychloroquine and immunosuppressant agents may be protective and beneficial treatment strategy in these patients need further investigation.

References:

[1] Gladman DD, Urowitz MB, Keystone EC. Serologically active clinically quiescent systemic lupus erythematosus: a discordance between clinical and serologic features. Am J Med 1979; 66:210-5.

[2] Huang WN, Tso TK, Wu HC, Yang HF, Tsay GJ. Impaired phagocytosis of apoptotic cell material in serologically active clinically quiescent patients with systemic lupus erythematosis. Int J Rheum Dis 2016; 19:1310-6.

[3] Steiman AJ, Gladman DD, Ibañez D, Urowitz MB. Prolonged serologically active clinically quiescent systemic lupus erythematosus: frequency and outcome. J Rheumatol 2010; 37:1822-7.

Disclosure of Interests: None declared

DOI: 10.1136/annrheumdis-2020-eular.4241

\section{AB0381 THE UTILITY OF HYDROXYCHLOROQUINE (HCQ) THERAPY FOR TWO YEARS AS A SPARING CORTICOSTEROID AGENCY IN PATIENTS WITH SYSTEMIC LUPUS ERYTHEMATOSUS (SLE)}

K. Inoue ${ }^{1}$, K. Misaki ${ }^{1}$, N. Dobashi ${ }^{1}$, M. Miyazaki ${ }^{1}$, Y. Mako ${ }^{1}$, T. Yusuke ${ }^{1}$ Y. Imaizumi ${ }^{2} .{ }^{1}$ Kitaharima Medical Center, Rheumatology, Ono, Japan;

${ }^{2}$ Kitaharima Medical Center, Center of Rheumatology, Ono, Japan

Background: Prednisolone (PSL) and HCQ are key drugs in the therapy of SLE. However, since PSL induce many harmful adverse events, PSL is preferred to be reduced especially in the maintenance therapy. The efficacy of $\mathrm{HCQ}$ for reducing the dose of PSL has not been revealed yet. So, we focused on the cessation of PSL under the treatment of HCQ with conventional SLE therapy.

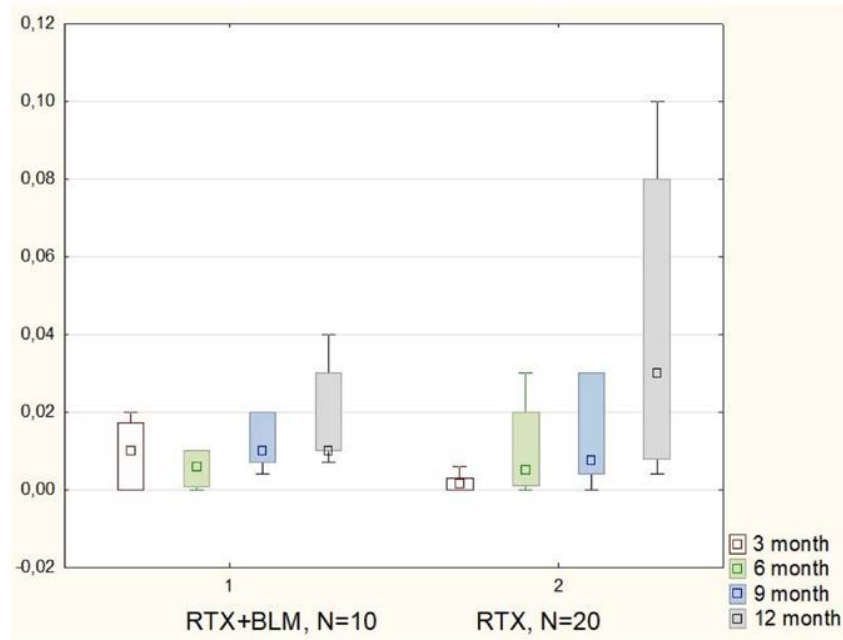


Objectives: The aim of this study is to evaluate the efficacy and the safety of $\mathrm{HCQ}$ as co-treatment in the standard therapy of SLE.

Methods: SLE patients $(n=30)$ under the maintenance therapy were enrolled in this study. Dose of PSL, titer of anti-DNA antibody, WBC count, serum complement and SLE disease activity index (SLEDAI) were examined retrospectively at 0 and 12 months after administration of $\mathrm{HCQ}$.

Results: Baseline patient-characteristics are as follows (mean \pm S.E); the age of patients was $54.4 \pm 3.2$ years old, 21 patients $(70 \%)$ were female, the disease duration was $108.5 \pm 25.2$ months, SLEDAI was $4.0 \pm 0.9$, the dose of PSL was $10.3 \pm 1.7 \mathrm{mg} /$ day, the titer of anti-DNA antibody was $7.3 \pm 1.8 \mathrm{IU} / \mathrm{ml}$, C3 was $85 \pm 4.3 \mathrm{mg} / \mathrm{dl}$ and $\mathrm{C} 4$ was $18 \pm 1.6 \mathrm{mg} / \mathrm{dl}$.

The mean dose of PSL was reduced with statistically significance (pre-administration of $\mathrm{HCQ}: 10.3 \pm 1.7 \mathrm{mg} /$ day, 24 months after administration of $\mathrm{HCQ}: 2.2 \pm 0.3 \mathrm{mg} /$ day, $p<0.0001)$. Furthermore, in this observation period, 6 patients could achieve the cessation of PSL.

SLEDAI was also significantly reduced $(4.0 \pm 0.9$ vs $1.0 \pm 0.3, p<0.01)$.

There was no statistical significance between before treatment by HCQ and after treatment in the titer of anti-DNA antibody $(7.3 \pm 1.8$ vs $2.8 \pm 1.6 \mathrm{IU} / \mathrm{ml}, p=0.06)$, WBC count $(6208 \pm 4.9$ vs $5096 \pm 3.3 / \mu \mathrm{l}, p=0.06)$ and serum complement level (C3 $85 \pm 4.3 \mathrm{mg} / \mathrm{dl}$ vs $89 \pm 4.0 \mathrm{mg} / \mathrm{dl}, p=0.52$, C4 $18 \pm 1.6 \mathrm{mg} / \mathrm{dl}$ vs $19 \pm 1.4 \mathrm{mg} / \mathrm{dl}$, $p=0.45)$. Relapse of SLE was clarified in only one patient.

As for adverse events (AEs), Severe bacterial infection $(n=4)$, herpes zoster $(n=1)$ and patellar tendon rupture $(n=1)$ were revealed. All cases of the AEs were fully recovered. Conclusion: Our study suggested that co-treatment with HCQ on standard SLE therapy could be enable to prevent the flare of SLE and reduce the dose of PSL with statistical significance. In some cases, we could achieve the cessation of PSL treatment References: None.

Disclosure of Interests: None declared

DOI: 10.1136/annrheumdis-2020-eular.5277

\section{AB0382 \\ A RITUXIMAB AND BELIMUMAB COMBINATION THERAPY IN SLE PATIENTS.}

A. Mesnyankina ${ }^{1}$, S. Solovyev ${ }^{1}$, E. Aseeva ${ }^{1}$, N. Nikishina ${ }^{1}{ }^{1}$ VA Nasonova Research Institute of Rheumatology, Moscow, Russian Federation

Background: Various mechanisms of action of RTM and BLM, in particular their interaction with defined subpopulations of B cells, can contribute to more effective suppression of autoreactive $B$ cells and achieve a therapeutic effect.

Objectives: To assess the efficacy of a rituximab and belimumab combination therapy in pts with active SLE.

Methods: The study included 10 SLE pts (1M/9F) with high (SLEDAI2K $\geq 10-8 p t s$.) and moderate (SLEDAI2K<10-2pts.) disease activity; out of them 2 patients had lupus nephritis, 2- vasculitis. 1 pts both (nephritis and vasculitis), and remaining 5 had predominantly mucocutaneous and articular manifestations of SLE. The dose of oral GCs at baseline did not exceed $20 \mathrm{mg} /$ day in 9 pts, two pts were treated with prednisone $5 \mathrm{mg} /$ day and only 1 received $60 \mathrm{mg}$. Rituximab (RTM) was administered at $500-2000 \mathrm{mg}$, with subsequent adding of Belimumab (BLM) 1-6 months later at a standard dosing regimen $10 \mathrm{mg} / \mathrm{kg}$ once a month. CD19+ B- lymphocytes counts were obtained before initiation RTM (0), and subsequently after $3(\mathrm{~N}=10)$, $6(\mathrm{~N}=10), 9(\mathrm{~N}=7)$, and 12month $(\mathrm{N}=7)$. Depletion of CD19+ B- lymphocytes after RTM was assessed as the decrease of $B$-cell counts $<0,0110^{*} 9 / /$, where $010^{*} 9 / /$ was categorized as complete depletion, from 0,001 to $0,0110^{\star} 9 / \mathrm{l}$ - partial depletion, and $>0,01110^{*} 9 / l-$ absence of depletion. The comparison group included $20 \mathrm{pts}$ receiving a sing $=\mathrm{b} 500-2000 \mathrm{mg}$ dose of $\mathrm{RTM}$ with high (SLEDAI2K $\geq 10-16 \mathrm{pts}$.) and moderate (SLEDAI2K<10- 4pts.) disease activity (SLEDAI Me 14[10;16])

Results: 6 pts demonstrated the decrease in clinical and laboratory SLE activity, starting from $3 \mathrm{mo}$ of follow-up, and by the 6 th month the decrease in the activity of the disease was observed in 9 patients (SLEDAI-2K 0 mo-Me 12[10;16], 3mo-Me 8[6;10], 6mo-Me 4[2;6], 9mo-Me 6[4;10], 12mo-Me 2[2;6]) with RTM + BLM combination therapy. The oral GCs dose was reduced to 6,9 $[5 ; 10] \mathrm{mg} /$ day by $6 \mathrm{mo}$. One patient managed to completely eliminate glucocorticoids; he continued to receive cytostatic therapy (mycophenolate mofetil). None of the patient required prednisone dose escalation during follow-up. There were no cases of severe infection. The damage index did not increase by 6 and $12 \mathrm{mo}$. The combination therapy reduced the absolute counts of CD19+. B-cells. RTM therapy resulted in complete depletion in 3 pts, in partial depletion - in 4. Addition of BLM resulted in slowing down of CD19+ B-cell repopulation (Fig.1) (0moMe $0,11 \times 10^{9} /[0,08 ; 0,5], 12 \mathrm{mo}-$ Me $\left.0,01 \times 10^{9} /[0,01 ; 0,03]\right)$ vs pts receiving RTM

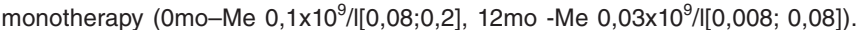
RTM and BLM combination failure, as well as failure of standard GCS and cytostatic based therapy, was documented in one patient with cutaneous, articular and hematological SLE.

Conclusion: Combination therapy allows to gain control over disease activity in short time, due to the effect of RTM, while added BLM provides further prolongation of the effect achieved, minimizing the risk of exacerbation. This combination may be used as a method of choice in pts with severe SLE involving vital organs, and in persistent cutaneous-articular disease and high immunological activity. In these patients there were no signs of infection.

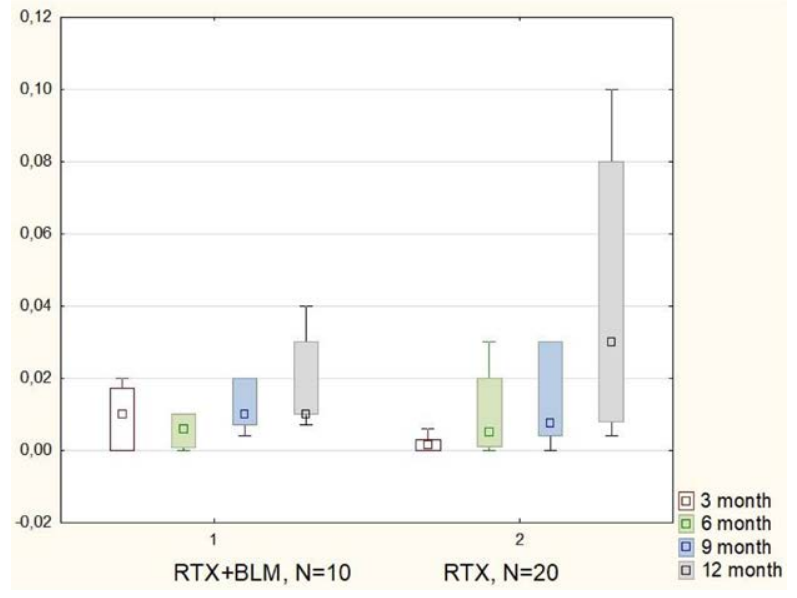

Figure 1.

Disclosure of Interests: None declared

DOI: 10.1136/annrheumdis-2020-eular.4217

\section{$\mathrm{AB} 0383$ \\ EXTREME FATIGUE IN PATIENTS WITH SYSTEMIC LUPUS ERYTHEMATOSUS AND NEUROPSYCHIATRIC SYMPTOMS}

R. Monahan ${ }^{1}$, R. Fronczek ${ }^{2}$, J. Eikenboom ${ }^{3}$, H. Middelkoop ${ }^{2}$, L. J. J. Beaart- van de Voorde $^{1}$, G. Terwindt ${ }^{2}$, N. Van der Wee ${ }^{4}$, T. Huizinga ${ }^{1}$, M. Kloppenburg ${ }^{1}$, G. M. Steup-Beekman ${ }^{1} .{ }^{1}$ Leiden University Medical Center, Rheumatology, Leiden, Netherlands; ${ }^{2}$ Leiden University Medical Center, Neurology, Leiden, Netherlands; ${ }^{3}$ Leiden University Medical Center, Internal Medicine, Division of Thrombosis and Hemostasis, Leiden, Netherlands; ${ }^{4}$ Leiden University Medical Center, Psychiatry, Leiden, Netherlands

Background: Fatigue is commonly described in chronic illnesses, especially auto-immune disorders such as systemic lupus erythematosus (SLE).

Objectives: We aim to study the prevalence of fatigue in SLE patients with NP symptoms and compare fatigue in SLE patients with NP symptoms attributed to major organ involvement due to SLE (NPSLE) with SLE patients with NP symptoms not caused by major nervous system involvement (non-NPSLE).

Methods: All patients visiting the tertiary referral center for NPSLE in the LUMC between 2007-2019 with the clinical diagnosis of SLE and age $>18$ years that signed informed consent were included in this study. Patients underwent a standardized multidisciplinary assessment, including two questionnaires: SF-36 (2007-2019) and multidimensional fatigue index (MFI, 2011-2019). Patients were classified as NPSLE in this study if NP symptoms were attributed to SLE and immunosuppressive or anticoagulant therapy was initiated, otherwise patients were classified as non-NPSLE. The vitality (VT) domain of the SF-36 domain was used to assess fatigue, which generates a score from 0-100, 100 representing the complete absence of fatigue. Patients with a score more than 1 standard deviation (SD) removed from age-related controls of the Dutch general population were classified as fatigued; patients more than 2 SD removed were classified as extremely fatigued ${ }^{1}$. The MFI was also used, which consists of 5 subdomain scores between $0-20$, leading to a total score between $0-100,100$ representing the most extreme fatigue. All scores are presented as mean and standard deviation. Results: 373 patients fulfilled the inclusion criteria and SF-36 questionnaires of 328 patients were available (88\%). The majority of these patients was female $(87 \%)$ and 98 were classified as NPSLE (30\%). In NPSLE patients, average age was 41 \pm 13 years and in non-NPSLE the average age was $45 \pm 14$ years. The average score of the SF-36 vitality domain was $36.0 \pm 20.7$ in NPSLE vs $33.9 \pm 18.8$. in nonNPSLE. Overall, $73.5 \%$ of the patients were fatigued and $46.9 \%$ extremely fatigued in NPSLE vs $77.8 \%$ fatigued and $45.7 \%$ extremely fatigued in non-NPSLE. The MFI questionnaire and VAS score were available for 222 patients, of which 65 patients were classified as NPSLE (29.3\%). Table 1 depicts the scores of NPSLE and non-NPSLE patients on the MFI subdomains and the VAS score.

Table 1. Fatigue in NPSLE and non-NPSLE patients $(\mathrm{N}=\mathbf{2 2 2})$

\begin{tabular}{lcc}
\hline & NPSLE (N = 65) & Non-NPSLE (N = 157) \\
\hline MFI (mean, sd) & & \\
General Fatigue & $10.8(1.8)$ & $11.1(1.5)$ \\
Physical Fatigue & $11.4(2.4)$ & $12.3(1.9)$ \\
Reduced Activity & $9.6(2.9)$ & $10.7(2.2)$ \\
Reduced Motivation & $10.7(2.6)$ & $11.1(1.9)$ \\
Mental Fatigue & $9.5(3.0)$ & $9.8(2.7)$ \\
Total score & $51.8(9.9)$ & $54.9(6.9)$ \\
SF-36 Vitality (mean, sd) & $35(20.7)$ & $32.7(18.2)$
\end{tabular}

